\title{
Optimal Vehicle Selection in the Design of Urban Energy Systems: An Integration of the Private Transport and Building Energy Sectors
}

\author{
Portia Murray $^{1,2}$, Kristina Orehounig ${ }^{2}$, Jan Carmeliet ${ }^{1}$ \\ ${ }^{1}$ ETH Zürich, Chair of Building Physics, Zürich, Switzerland \\ ${ }^{2}$ Urban Energy Systems Laboratory, Empa, Dübendorf, Switzerland
}

\begin{abstract}
An optimization model has been built to select the optimal combination of vehicle technologies, charging and building system technologies for a group of 52 buildings and 82 cars in Switzerland. The multiobjective optimization reduces both total costs and total emissions and performs both a selection of vehicle, building, charging and storage technologies as well as operation over one year. The car selection chooses from internal combustion engine, hybrid, battery electric, and fuel cell vehicles. The building optimization can select a combination of gas-boilers, fuel cells, heat pumps, and electrolysers to enable meeting both heating demands, electricity demands, and vehicle demand requirements. The results indicate that both heat pumps and battery vehicles are the lowest cost technologies that significantly reduce carbon emissions; however, there are cases where fuel cell vehicles and hybrid vehicles may be a better alternative depending on charging and driving requirements.
\end{abstract}

\section{Introduction}

When building energy consumption is analysed, usually only electricity, heating, and cooling demands are considered. Personal transport is typically considered a separate sector to buildings and the process of reducing carbon emissions in these two sectors are usually investigated separately. However, new improvements in alternative vehicles (i.e., hybrid, battery, and fuel cell vehicles) now includes a concept where charging infrastructure for personal vehicles are located in buildings or at a community charging station. With the promotion of rooftop photovoltaics in communities, this renewable energy has the potential to be not only used for building electricity, cooling, or heating, but also to charge vehicles.

Although nearly $28 \%$ of the total end use energy demand in 2015 in Switzerland came from building usage, another $26 \%$ of this energy came from road based passenger transportation (Raubel et al. 2014). The energy required to operate personal vehicles represents a significant contribution of greenhouse gas emissions per capita in most developed countries. With the growing popularity of electric vehicles and the potential for further expansion of the commercial fuel cell market in the future, charging stations within communities can be included in order to further reduce greenhouse gas emissions from consumers and to extend the reach of renewable energy to the personal transportation sector.

In a previous study, we have used multi-optimization to select the size, configuration, and operation of a selection of conversion (heat pumps, boilers, photovoltaics, fuel cells, electrolysers, etc.) and storage technologies (batteries, thermal, and hydrogen storage) to meet the electrical and heating demand of a multienergy system placed within a community of buildings (Murray et al. 2017). In this work, personal vehicles and their charging demands (measured in kilometres) are included as an additional load. The optimization includes the selection of the car from four types: an internal combustion engine vehicle (ICEV), fuel cell electric vehicle (FCEV), battery electric vehicle (BEV), and plug-in hybrid vehicles (PHEV).

This paper introduces energy charging demand for several different vehicle types within the energy systems of communities. The aim is to identify potential synergies that exist between hydrogen system designed to provide simultaneous vehicle and stationary building demands. Including personal vehicle charging could allow for further flexibility of the system by providing potential demand response.

There are many studies in recent years that look into the optimal integration of BEV or PHEVs into the systems within a home's building systems (Tanguy et al. 2016 and Wi et al. 2013) and the integration of FCEV's into commercial building complexes (Hajimiragha et al. 2007). These investigations are important; however, they only look at the possibility of one or two types of vehicle and charging with a single energy carrier.

There are also several papers (e.g., Offer et al. 2010) that have looked into an optimization or another evaluation of different vehicle types in purely a transportation context, however the integration with a buildings systems is neglected. In this paper, our proposed model aims to link the selection and operation of building conversion technologies and storage systems with the selection and operation of four different types of vehicles. This model does not attempt to be a holistic model of both building and transport sectors, but rather attempts to investigate the optimal synergies between buildings and personal vehicles within decentralized energy systems. The carbon emissions of the building occupant's vehicle usage are usually neglected from the calculation of a building's carbon footprint, however in 
the context where vehicles are charged at home or at a community charging station, this is now included in the analysis. A case study of 52 buildings and 82 vehicles is then used to test the analysis for several different scenarios for vehicle selection. This case study is described in the Case Study section.

\section{Methodology}

This work combines several different models into a workflow to assess the performance of both the building and the charging of personal transport. From an initial building stock, the electricity and heating demands are calculated with a the building stock model from Wang et al. (2018). The available area for solar radiation and the incidence are then calculated using a GIS analysis and LiDaR raster data using the technique developed in Mavromatidis et al.(2015). A random forest model is then used to determine the car ownership rate, and the driving profiles of households according to the Swiss Mobility Census data (Bundesamt für Statistik 2015). Lastly, the renewable potential, the building loads, the number of vehicles, and their vehicle demands are then input into a multi-objective optimization that minimizes both total cost and total emissions. Figure 1 shows the overall workflow of this methodology.

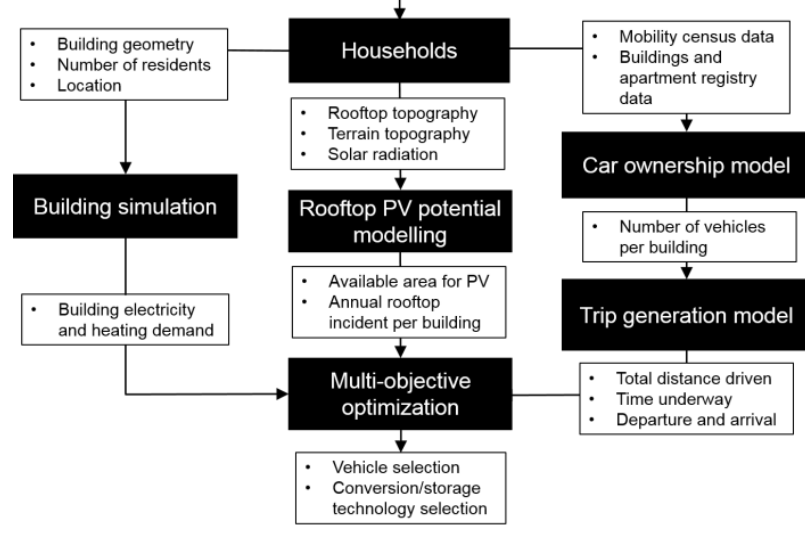

Figure 1: Flow of information between the different models in the paper.

\section{Multi-Energy System Optimization}

A multi-energy system (MES) is an energy system that utilizes several different energy carriers to meet a set of demands. These energy carriers can be converted from one to another or stored. The optimization of multienergy systems in this paper is performed using a mixed integer linear program that balances energy carriers from energy potential to energy demand. These energy carriers include heat, electricity, hydrogen, natural gas, gasoline, and carbon dioxide. It is noted that, although $\mathrm{CO}_{2}$ is not technically an energy carrier, it is used in this simulation in methanation to make methane, so it is treated the same as an energy import. These energy carriers can be converted, via conversion technologies or stored within the system, as shown in Figure 2. The model is then optimized using the epsilon constraint method (Laumanns, 2006) to minimize both total costs and total emissions. The calculations for both of these are shown in Eq. 1 and Eq. 2 respectively. Ten Pareto optimal solutions are calculated for this work, in order to show a variety of intermediate solutions.

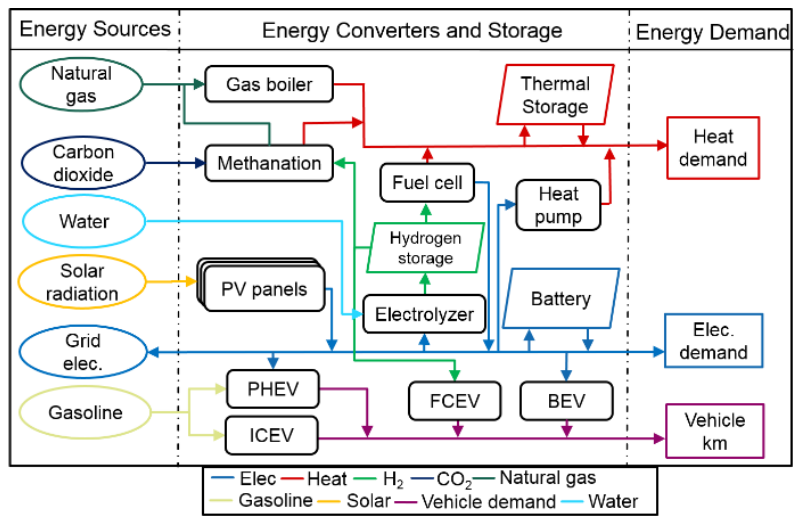

Figure 2: Schematic of the optimization model including energy potentials on the left, conversion and storage technologies in the middle, and energy demands on the right.

$$
\text { Total }_{\text {Cost }}=\sum_{v}^{V} \sum_{c}^{C} \text { CapCost }_{v, c}+\sum_{t}^{T} \text { CapCost }_{t}+
$$
$\sum_{s}^{S}$ CapCost $_{s}+\sum_{t}^{T} O M F_{t} P_{t}^{C a p}+\sum_{t}^{T} O M V_{t} \sum_{h}^{H} P_{t, h}^{o u t}+$ $\sum_{h}^{H} \sum_{f}^{F} P_{f, h}^{\text {Import }}{ }^{\text {Price }}$ Import $_{f}-\sum_{h}^{H} \sum_{f}^{F} P_{f, h}^{\text {Export }}$ Price Export $^{\text {Exp }}$

$$
\text { Total }_{\text {Emissions }}=\sum_{h}^{H} \sum_{f}^{F} P_{f, h}^{\text {Import }} C F_{f}
$$

In Eq. 1 and 2, $V$ represents the set of vehicle technologies, $C$ represents the number of vehicles, $T$ represents the set of both conversion technologies, $S$ is the set of storage technologies, $H$ represents the hourly time steps, and $F$ represents the set of energy carriers. CapCost is the capital costs of each of the respective technologies or vehicles, which are calculated with Eq. 3. $O M V$ are the variable operation and maintenance (O\&M) costs which are dependent on the yearly output of operation of each technology, and $P$ represents the hourly power produced from a conversion technology, energy imported into the system, or energy exported from the system (buying and selling is restricted to only the electricity and natural gas carriers). $C F$ represents the carbon factor of each energy carrier when purchased.

CapCost $_{v / t}=\operatorname{Inv}_{v, t} \frac{d}{\left(1-\frac{1}{(1+d)^{i}}\right)}$

Here, $d$ is the discount rate (assumed to be 0.08), $I$ is the lifetime of the technology in years, and $I n v$ is the initial investment cost.

The capital costs are dependent on the selected technology capacities, which are decision variables in the optimization.

\section{Usage profiles and Temporal Reduction}

This simulation is performed over a year, thus many decision variables occur within energy hour of the simulation. A full year time horizon, or 8760 hours, can make the model very computationally intensive, resulting in long run times. A temporal reduction technique, call the "Typical days" approach, is commonly employed in MES optimization models (Marquant, Evins, and Carmeliet 2015). Using this method, the k-medoid clustering approach is used to select $N_{k}$ user chosen typical days to represent the full 
year's heating demand, electricity demand, solar production, and vehicle demand. In this paper, 12 representative days were chosen. In addition, the peak days for the four input profiles (electricity demand, heating demand, vehicle demand, and solar radiation) are also included in order to include technologies sized for for maximum loads and to include extreme cases of operation. This results in a reduction from a full horizon of 8760 hours to 384 hours.

\section{Conversion Technologies}

The conversion technologies used in the model include gas boilers, photovoltaic (PV) panels, heat pumps, fuel cells, electrolysers and a catalytic methanation reactor (CMR). The basic heating technologies are represented by the gas boiler (the existing heating system of the buildings) and the heat pumps. For a hydrogen system, electrolysers can be used to produce hydrogen from either surplus electricity or purchased electricity. This hydrogen can then be stored in compressed tanks (700 bar) and then used to charge FCEV vehicles, used in stationary fuel cells to produce both local electricity and heat, or used in methanation with $\mathrm{CO}_{2}$ to produced natural gas, which can then be used in gas boilers or sold to the natural gas grid.

Polymer electrolyte membrane electrolysers (PEME) and polymer electrolyte membrane fuel cells (PEMFCs) are chosen due to the fast response times and flexibility of these devices (Götz et al. 2016). Due to the placement of the site near biogas facilities, it is assumed that $\mathrm{CO}_{2}$ is available on this site for purchase and use in the methanation reaction at a rate of $0.06 \mathrm{CHF} / \mathrm{kg}$ (Kuramochi et al. 2012). The catalytic methanation reactors also produce heat due to the high temperatures, which can then be transferred to the heating system. Table 1 describes the represented efficiencies and costs of the considered conversion technologies. The operation of each technology in an hour is restricted by the constraint in Eq. 4.

$\operatorname{Cap}_{t} \geq P_{t, f, h}^{\text {out }} \forall t \in T, h \in H, f \in F$

The operation of each technology is also restricted by start-up times and reduced performance on start-up. This is specific to the CMR, the PEMFC, and the PEME, which have start-up times of 30,8 , and 3 minutes respectively. Due to this, the production of these devices on start-up is limited and an auxiliary term is used to represent the energy consumption on start-up.

\section{Storage Technologies}

There are three storage technologies that can be stored on site (not including the fuel tanks or batteries in vehicles): batteries, thermal energy storage (TES), and hydrogen storage $(\mathrm{H} 2 \mathrm{~S})$. In order to store hydrogen, the gas must be compressed up to 700 bar, which includes compression losses of $80 \%$ on charging. The energy balance on the battery, thermal, and hydrogen storages is shown in Eq. 5.

$$
\begin{aligned}
& E_{h}=E_{h-1} \text { Decay }+\eta_{\text {Charging }} E_{\text {in }}- \\
& \frac{1}{\eta_{\text {Discharging }}} E_{\text {Out }} \forall h \in H
\end{aligned}
$$

Decay is the hourly decay of the state of charge, and $\eta$ is the charging or discharging efficiency. The decay of the battery, thermal storage, and hydrogen storages are assumed to be $0.1 \%, 1 \%$, and $0 \%$ respectively. The charging efficiencies are $92 \%, 90 \%$, and $95 \%$ and the discharging efficiencies are $92 \%, 90 \%$, and $100 \%$. When the hydrogen storage charges, it is also assumed that there is a required compressor electricity load of 2.8 $\mathrm{kWh} / \mathrm{kg} \mathrm{H}$.

Table 1: Technical and economic parameters of the conversion

\begin{tabular}{|c|c|c|c|c|}
\hline Tech. & Eff. & Capital costs & $\begin{array}{l}\text { O\&M } \\
\text { Costs }\end{array}$ & Lifetime \\
\hline $\begin{array}{c}\text { Gas } \\
\text { boiler }\end{array}$ & 0.9 & $\begin{array}{c}400 \\
(\mathrm{CHF} / \mathrm{kW})\end{array}$ & $\begin{array}{c}3 \\
\mathrm{CHF} / \mathrm{kW}\end{array}$ & 25 years \\
\hline $\begin{array}{l}\text { Heat } \\
\text { pump }\end{array}$ & 3 & $\begin{array}{c}1200 \\
(\mathrm{CHF} / \mathrm{kW})\end{array}$ & $\begin{array}{c}5 \\
\mathrm{CHF} / \mathrm{kW}\end{array}$ & 20 years \\
\hline PV & 0.17 & $\begin{array}{c}2380 \\
(\mathrm{CHF} / \mathrm{kW})\end{array}$ & $\begin{array}{c}40 \\
\mathrm{CHF} / \mathrm{kW}\end{array}$ & 25 years \\
\hline $\begin{array}{l}\text { PEM- } \\
\text { E }\end{array}$ & 0.7 & $\begin{array}{c}3500 \\
(\mathrm{CHF} / \mathrm{kW})\end{array}$ & $\begin{array}{c}0.025 \\
\mathrm{CHF} / \mathrm{kWh}\end{array}$ & $\begin{array}{c}60,000 \\
\text { hours }\end{array}$ \\
\hline $\begin{array}{l}\text { PEM- } \\
\text { FC }\end{array}$ & $\begin{array}{c}\text { Elec: } \\
0.52 \\
\text { Heat: } \\
0.43\end{array}$ & $\begin{array}{c}4400 \\
(\mathrm{CHF} / \mathrm{kW})\end{array}$ & $\begin{array}{c}0.025 \\
\mathrm{CHF} / \mathrm{kWh}\end{array}$ & $\begin{array}{c}60,000 \\
\text { hours }\end{array}$ \\
\hline CMR & 0.73 & $\begin{array}{c}2000 \\
(\mathrm{CHF} / \mathrm{kW})\end{array}$ & $\begin{array}{c}20 \\
\mathrm{CHF} / \mathrm{kW}\end{array}$ & 15 years \\
\hline Bat. & 0.92 & $\begin{array}{c}600 \\
(\mathrm{CHF} / \mathrm{kWh})\end{array}$ & $\begin{array}{c}25 \\
(\mathrm{CHF} / \mathrm{kW} \\
\mathrm{h})\end{array}$ & 10 years \\
\hline TES & 0.81 & $650\left(\mathrm{CHF} / \mathrm{m}^{3}\right)$ & - & 17 years \\
\hline $\mathrm{H} 2 \mathrm{~S}$ & 0.95 & $\begin{array}{c}22 \\
(\mathrm{CHF} / \mathrm{kWh})\end{array}$ & - & 20 years \\
\hline
\end{tabular}
and storage technologies used in the model.

\section{Vehicle Demand}

The number of vehicles per household is assigned to households using a random forest model developed from the Swiss Mobility Micro census data from 2015 (Bundesamt für Statistik 2015). This data includes vehicles and regular driving routes of almost 60,000 households in Switzerland. From this data, combined with the Swiss Buildings and Apartment Registry data (Bundesamt für Statistik, 2013), the random forest model was trained to predict the number of vehicles depending on the following data:

1. Household size

2. Household income

3. Building type (single family, multi-family, etc.)

4. Number of units in the buildings (if multifamily)

5. Total number of people in the building

6. Household type (single person, couple, couple with children, single parent, etc.)

7. Canton

8. Population of town

There are 45,452 households with good quality information in all these categories. One-hot encoding was used for categorical parameters such as building and 
household type. The simulation set was trained on $75 \%$ of the full data set and tested on the remaining $25 \%$. The data set was trained using Scikit-learn random forest function with 100,000 estimators and a minimum sample leaf of 65 . The prediction accuracy of the testing data set is shown in Table 2 .

Table 2: Random forest model prediction.

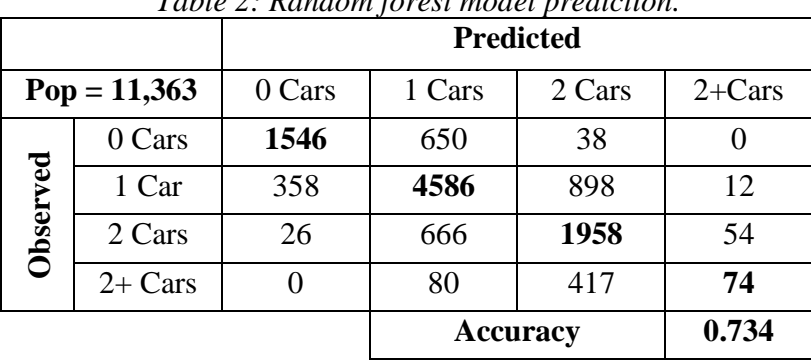

The accuracy of this prediction is determined to be $73 \%$ on a per household basis, but the accuracy of predicting the total number of vehicles in a community correctly is above $98 \%$. Considering the diversity of households across the country, this was determined to be satisfactory for this study. Once the number of cars per household is determined, the driving profiles are assigned. All vehicles in the simulation are associated with load profiles. The load profiles for the vehicles have two pieces of information. Firstly, the vehicles have a binary value $\left(\delta_{\text {Charge }}\right)$ to indicate when they are available to charge. Secondly, the vehicles have the distance in kilometres driven in each hour of the day for a typical workweek. A typical driving profile for a single day is shown in Figure 3.

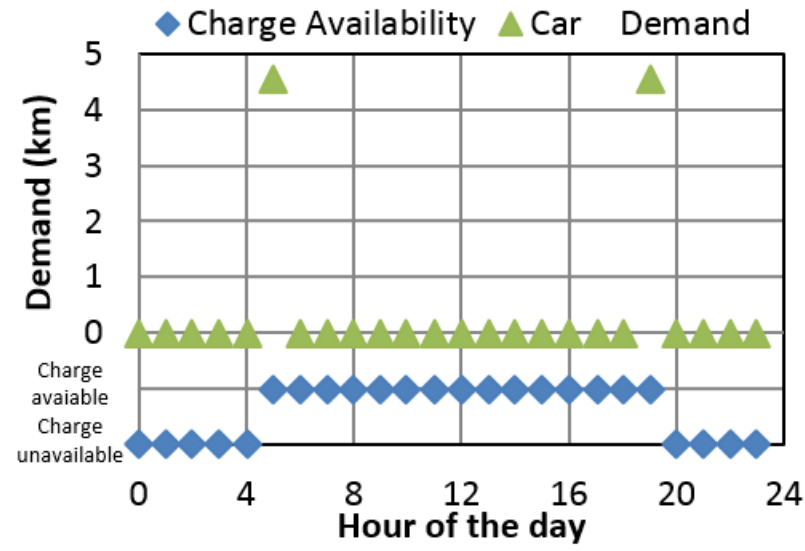

Figure 3: Example of a typical driving profile for a workday. The charge availability is a binary value representing if the vehicle is home or away and the demand is the driving kilometres required by the vehicle at a certain time.

These profiles are sampled from the actual mobility census profiles of households in the mobility data set that have the same eight parameters used for the random forest model for each of the vehicles assigned to a household.

\section{Vehicles Selection}

Four different vehicles can be optimized in the model. These include internal combustion engine vehicles (ICEV), plug-in hybrid electric vehicles (PHEV), battery electric vehicles (BEV), and fuel cell electric vehicles
(FCEV). All vehicles are assumed to be mid-size vehicles in the same weight class.

Both ICEV and PHEV vehicles can refill their gasoline requirements at gas stations. The batteries within the PHEV and BEV vehicles are charged at home within the communities. The FCEV is charged at a common hydrogen station installed in the community. It is noted that in this work, charging at external charging stations is not yet considered due to lack of data of workplace availability. This is noted as a current limitation of this methodology that will be addressed in future iterations of the model. Eq. 6, 7, and 8 describe the constraints for charging.

$P_{v, c, f h}^{\text {Charging }} \leq \delta_{\text {Charge }} P_{v, c, f}^{M a x} \forall c \in C, v \in V, f \in F$

$E_{c, v, f, h}^{\text {Storage }}=E_{c, v, f}^{\text {Storage }}+\eta_{\text {Charging }} E_{c, v, f, h}^{\text {Charging }}-$

$E_{c, v, f, h}^{\text {Disharging }} \forall C, V, F, H$

$E_{c, v, f, h}^{\text {Storage }} \leq E_{v, f}^{\text {Capacity }} y_{c, v}^{\text {Vehicles }} \forall c \in C, v \in V, f \in F, h \in$ $H$

In Eq. $6, P_{v, c}^{\text {Charging }}$ is the vehicle charging power and $P_{v, c, f}^{\operatorname{Max}}$ is the maximum charging power available. This limitation is $6.6 \mathrm{~kW}$ for BEVs and $3.2 \mathrm{~kW}$ for PHEV batteries. In Eq. 7, the storage level within vehicle batteries or fuel tanks is being maintained while driving or charging. $\eta_{\text {Charging }}$ or the charging efficiencies are assumed to be $92 \%$ for the battery charging, $100 \%$ for fuel cell vehicle charging, and $100 \%$ for gasoline charging. Lastly, in Eq. $8, E_{v, f}^{\text {Capacity }}$ is the maximum storage capacity of the vehicles and $y_{c, v}^{\text {Vehicles }}$ is the binary value that indicates which type of vehicle is installed for each assigned vehicle. $E_{v, f}^{\text {Capacity }}$ is defined per vehicle type in Table 3.

Table 3: Storage capacity of mid-sized vehicles

\begin{tabular}{|c|c|c|c|c|}
\hline & ICEV & PHEV & BEV & FCEV \\
\hline Gasoline & $543 \mathrm{kWh}$ & $425 \mathrm{kWh}$ & - & - \\
\hline Battery & - & $6.7 \mathrm{kWh}$ & $46 \mathrm{kWh}$ & - \\
\hline $\mathrm{H}_{2}$ tank & - & - & - & $5 \mathrm{~kg}$ \\
\hline
\end{tabular}

Since the PHEVs have two driving systems, it is assumed that the battery is discharged until $80 \%$ depth of discharge, after which the gasoline drive is then used.

The operational efficiency of the mid-vehicles under different driving conditions has been taken from the work of Hofer (Hofer 2014). In this work, the vehicle powertrain conditions have been simulated according to the Worldwide Harmonised Light Vehicle Test Procedure (WLTP) driving cycles, which has become the new standard cycle in Europe as of 2017. Table 4 shows the resulting consumption data according to this driving cycle that has been derived from the work of Hofer (2014). 
Table 4: Performance of all vehicle types simulated in the WLTP driving cycle.

\begin{tabular}{|c|c|c|c|c|}
\hline & ICEV & PHEV & BEV & FCEV \\
\hline Gasoline & $\begin{array}{c}1.28 \\
\mathrm{~km} / \mathrm{kWh}\end{array}$ & $\begin{array}{c}1.63 \\
\mathrm{~km} / \mathrm{kWh}\end{array}$ & - & - \\
\hline Battery & - & $\begin{array}{c}3.8 \\
\mathrm{~km} / \mathrm{kWh}\end{array}$ & $\begin{array}{c}3.8 \\
\mathrm{~km} / \mathrm{kWh}\end{array}$ & - \\
\hline $\mathrm{H}_{2}$ & - & - & - & $\begin{array}{c}72.5 \\
\mathrm{~km} / \mathrm{kg}\end{array}$ \\
\hline
\end{tabular}

In addition to the performance of the vehicles, the cost of the vehicles must also be considered. The capital costs of the mid-size vehicles considered are shown Table 5.

Table 5: Capital costs of vehicle technologies(Hofer 2014).

\begin{tabular}{|c|c|c|c|c|}
\hline & ICEV & PHEV & BEV & FCEV \\
\hline $\begin{array}{c}\text { Capital } \\
\text { Costs } \\
\text { (CHF) }\end{array}$ & 22,000 & 37,000 & 42,000 & 68,000 \\
\hline
\end{tabular}

Unlike stationary technologies, which assume lifetime in terms of years or hours, the lifetime of the vehicles is determined to be 200,000 kilometres, thus the predicted is determined by dividing it by the annual driving distance for each vehicle. This lifetime is then used in Eq. 3.

\section{System Boundaries}

The system analysed is considered decentralized, however it is able to interact with the centralized electricity and natural gas grids by both purchasing and selling electricity and natural gas if PV panels or methanation reactors are installed respectively. It is assumed in this model that electricity can be sold back to the grid at a rate of $0.1 \mathrm{CHF} / \mathrm{kWh}$ and that methane can be sold back to the natural gas grid at a rate of 0.09 $\mathrm{CHF} / \mathrm{kWh}$. Electricity can be purchased at a rate of 0.2 $\mathrm{CHF} / \mathrm{kWh}$ (ELCom 2018) and natural gas can be purchased at a rate of $0.09 \mathrm{CHF} / \mathrm{kWh}$ (Eidgenössisches Department für Wirtschaft 2018), which are the average prices in 2018 including the national carbon tax of 96 $\mathrm{CHF} /$ ton $\mathrm{CO}_{2}$ (FOEN 2018).
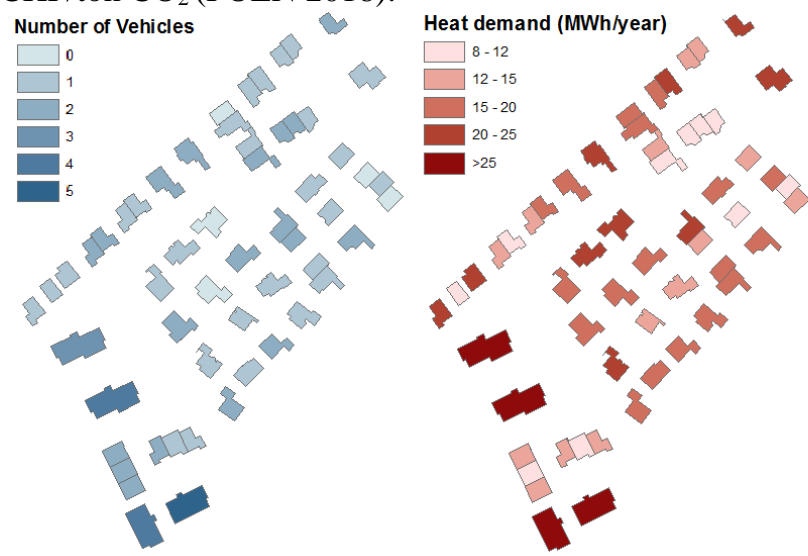

The final energy balance of the system is calculated with Eq. 9.

$$
\begin{aligned}
& P_{f, h}^{\text {Import }}+\sum_{t}^{T} P_{t, f, h}^{I n} \eta_{t, f}+P_{t, f, s}^{\text {Discharging }}=\sum_{b}^{B} P_{b, f, h}^{\text {Demand }}+ \\
& \sum_{c}^{C} \sum_{v}^{V} P_{c, v, f, h}^{\text {Charging }}+P_{f, h}^{\text {Export }} \forall f \in F, h \in H
\end{aligned}
$$

$B$ represents the set of buildings and $P_{b, f, h}^{\text {Demand }}$ is the building demand for either heat or electricity.

\section{Case Study}

Fifty-two buildings in a suburban town in Switzerland were used in this analysis. These buildings consist of four multi-family houses, 28 attached single-family houses and 20 detached single-family houses. The houses were mostly built in the mid-1980s to 90 s and are not retrofitted at this time. The demand from these buildings was simulated using the building stock model Wang et al. and the data from the Swiss Buildings and Apartment Registry (Bundesamt für Statistik, 2013). The geometry details were taken from the Swiss Buildings 2.0 dataset (Swisstopo 2014). Using this data the models for solar radiation and building demand cited in the methodology section are used. It was determined that the total area available for PV installation is $6998 \mathrm{~m}^{2}$ Lastly, the number of vehicles and driving profiles are assigned based on the methodology described in the Vehicle Demand section. The total number of vehicles was estimated to be 82 . The resulting calculations are shown in Figure 4.

As of 2018, the buildings currently use gas boilers to meet their heating demand, $30 \mathrm{~m}^{2}$ of PV is currently installed, and it is assumed that all vehicles are ICEVs. This data is used as the initial case for the optimization and the vehicles, their driving profiles, the building demand and renewable potential data is input into the model.

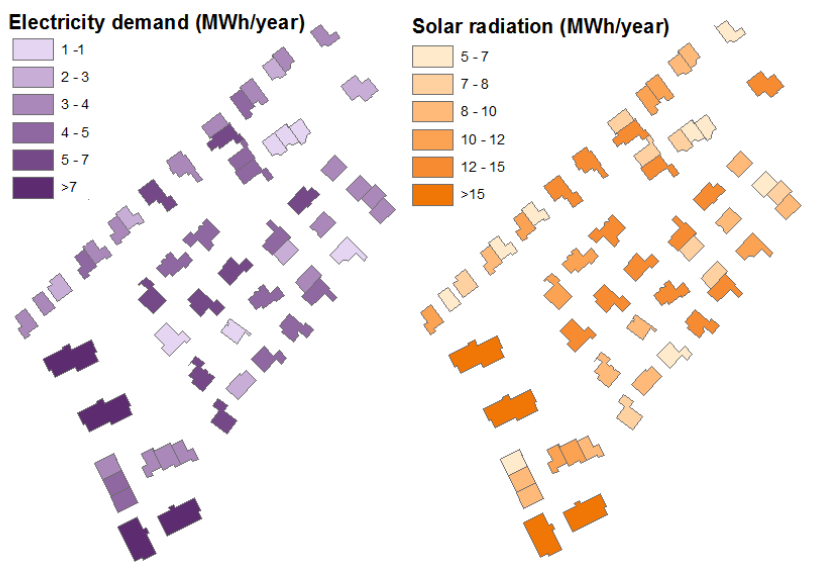

Figure 4: The number of vehicles, heating demand, electricity demand, and available solar radiation for 52 buildings.

\section{Simulation Scenarios}

In order to see a variety of solutions, five different scenarios are simulated.
1. ICEV with optimal selection of conversion and storage technologies in buildings

2. PHEV with optimal selection of conversion and storage technologies 
3. BEV with optimal selection of conversion and storage technologies

4. FCEV with optimal selection of conversion and storage technologies

5. Optimal selection of vehicles with optimal selection of conversion and storage technologies

\section{Results}

For the given case study of 52 buildings and 82 buildings, a multi-objective optimization was run using the epsilon constraint method to minimize both total costs and total emissions. This model optimizes for the selection of vehicle technologies, charging technology, and building technologies in order to meet the heating, electricity, and charging demands in the community. In the multi-objective analysis, ten Pareto optimal points are chosen. These points represent a spectrum of solutions ranging from the lowest cost and highest emitting solution (Point 1) to the highest cost and lowest emitting solutions (Point 10) for each of the scenarios described in the Simulation Scenarios section.

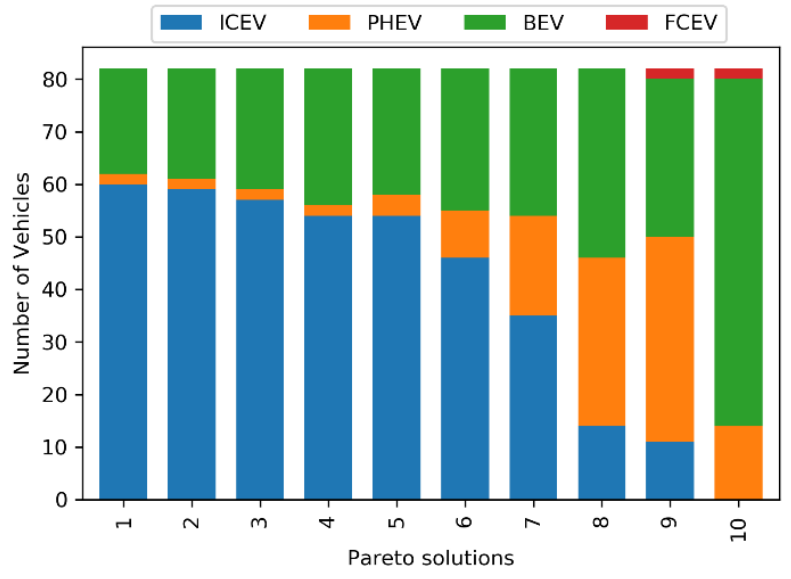

Figure 5: Selection of vehicle type for the 82 vehicles in the district for the optimal selection scenario.

Figure 5 shows the distribution of the selection of the vehicles for the optimal selection scenario. In Figure 5, it is shown that in the most cost optimal cases, approximately $75 \%$ of the vehicles are ICEV, $2 \%$ are PHEV, and $22 \%$ are BEV. FCEVs are only chosen for two vehicles in the solutions with the lowest carbon emissions. These two vehicles were associated with higher daily vehicle ranges that exceeded $180 \mathrm{~km}$. This is higher than the range of the battery vehicle, thus it was not feasible to install electric vehicles in this case and these vehicles benefited from the quick charging times and the longer range of the FCEV. The PHEV vehicles are selected for vehicles with short driving distances, as the battery in the PHEV was a sufficient for short journeys. Figure 6 shows the resulting selection of the stationary technologies.

In Figure 6, it is seen that the cost optimal selection is dominated by gas boilers (GB), with a few heat pumps being selected in the buildings. As $\mathrm{CO}_{2}$ emissions are minimized, heat pumps are increasingly installed. In addition, $\mathrm{PV}$ is installed in a small capacity in the cost optimal case, but this shifts to the full rooftop potential in the $\mathrm{CO}_{2}$ optimal case.

FCEV selection electrolysers are installed in small capacities in the cost optimal solutions and in larger capacities in the $\mathrm{CO}_{2}$ optimal solutions. Stationary batteries are often installed with the electrolyser to ensure an uninterrupted clean electricity supply from the PV panels to prevent shutdown. The BEV selection case was unable to install the vehicle for 2 cases as the users driving distance requirements were too much for the range of the vehicle, thus 2 ICEVs (cost optimal) 2 FCEVs $\left(\mathrm{CO}_{2}\right.$ optimal) are installed in the $\mathrm{BEV}$ selection case.

This results in the installed electrolysers in the BEV Selection point 10 . It is noted that neither the fuel cells nor the methane reactors are used. This is due to the PV potential being used directly to charge vehicles or to run the electrolyser for hydrogen fuel for vehicles. There is not enough excess PV potential in this case study to produce extra hydrogen for methanation. It may be feasible to install this technology if the electricity price was lower or if there was another source of renewable electricity

However, with the renewable production, high electricity price, and the high capital costs it is not yet feasible to install these technologies. The Pareto fronts, showing the Total cost and Total Emissions, are shown in Figure 7.

In Figure 7, it is seen that the ICEV selection scenario is the highest emitting scenario and has costs similar to the BEV scenario. The PHEV scenario has slightly lower emissions than the ICEV scenario, but higher costs than the ICEV or BEV. The FCEV scenario has significantly higher costs, but emissions only slightly higher than the BEV selection. The optimal selection performs closely to the $\mathrm{BEV}$ scenario in the $\mathrm{CO}_{2}$ optimal cases, although it is able to achieve lower costs and emissions than the BEV scenario in the intermediate solutions. The full break down of all costs and emissions are shown in Figure 8 .

Figure 8 shows the different costs by category, including capital costs, operation and maintenance costs, and the fuel costs. Gasoline and natural gas costs comprise a large portion of the cost in the ICEV selection case. The emissions of the ICEV case are largely attributed to gasoline and natural gas. The high costs in the FCEV case are attributed to much higher capital costs due to the expense of the FCEV vehicles. The conventional technology costs are also higher due to the installation of electrolysers. In addition, the electricity costs are highest in this section, due to the lower efficiency of charging the hydrogen vehicles via electrolyser vs. directly charging the BEVs with electricity. 

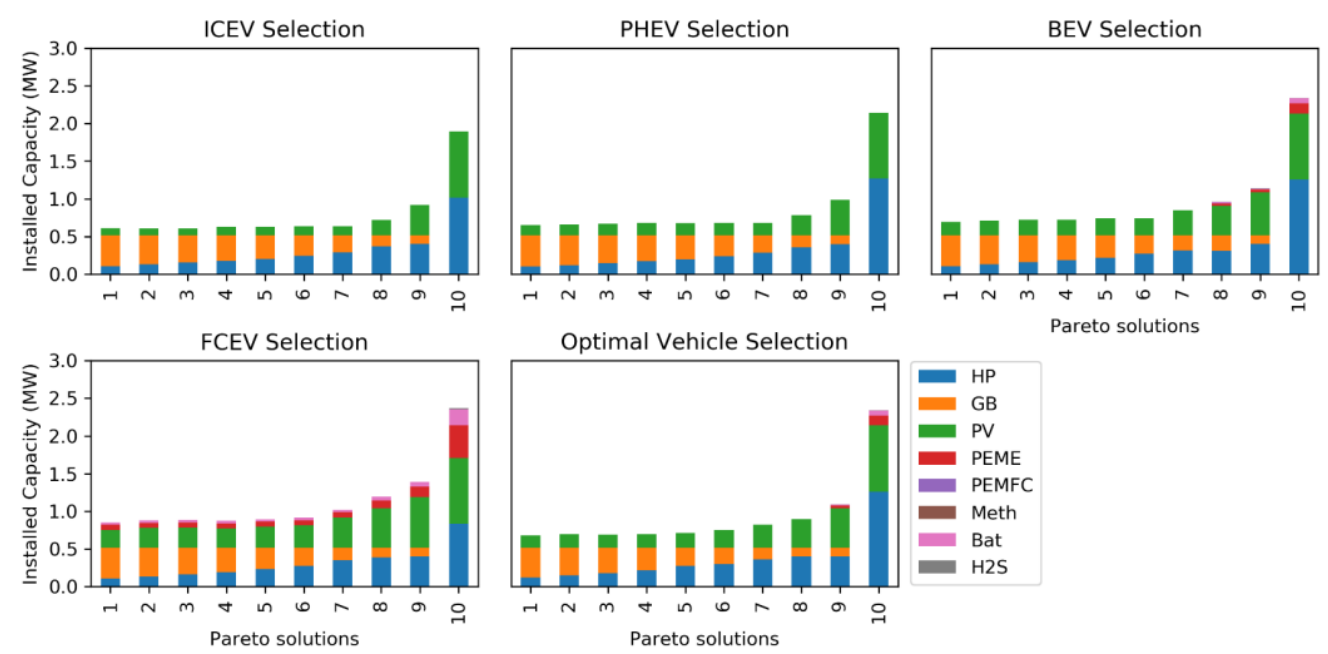

Optimal Vehicle Selection

Pareto solutions

Figure 6: Selection of the Conversion and Storage Technologies.

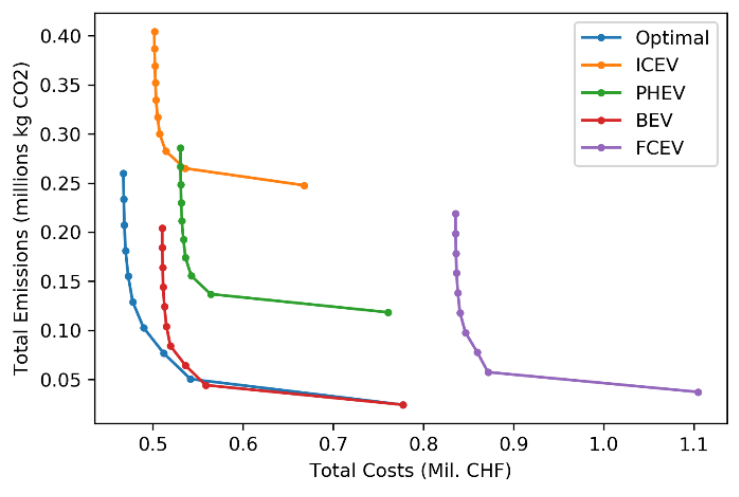

Figure 7: Total Cost and Total Emissions Pareto Front showing all scenarios.

From an emissions standpoint, the BEV scenario's emissions are slightly lower, although both solutions are effective at reducing emissions through utilization of rooftop PV. However, the lower cost of BEVs result in a much more economically feasible case.

The emissions case of the optimal selection case shows that the first step in reducing emissions from the cost optimal baseline is to switch from gas-boilers to heat pumps, and that the second is to replace ICEV vehicles with other vehicle types. The vehicle type replacement is highly dependent on the driving profile of the car owners.

\section{Discussion}

From the analysis of the results, it is observed that BEVs are the most attractive technology to replace our vehicles with in order to phase out ICEVs. Although it is the most attractive technology, the optimal technology selection did chose a mix of the three alternative type of vehicles depending on their driving profiles. For those who drive short distances, a PHEV can be a cheaper and just as effective as a BEV, as the battery is sufficient for short journeys, and the gasoline allows the driver to make certain long distance journeys. A daily commuter, who often drives often but less than the $175 \mathrm{~km}$ range of the $\mathrm{BEV}$, is best suited with a BEV. Lastly, there were two commuters in this analysis whose driving range could not be met through a BEV, thus the lower carbon alternative was chosen to be a FCEV.

Installation of PV systems is particularly important when trying to decarbonize BEV and FCEV technologies. If rooftop PV is not installed, it would be much harder to decarbonize due to the $\mathrm{CO}_{2}$ value of grid electricity. Lastly, it was observed that changing the heating system of a building from a fossil fuel boiler to a heat pump is generally a lower cost option than changing the transport system and installing new charging infrastructure, but both will be eventually necessary to decarbonize both the building stock and the personal transport sectors.

\section{Conclusion}

In this work, we have developed a multi-objective optimization model that selects the technology set for both the heating and renewable technology sets for a group of buildings, as well as the vehicle technology. The optimization simulates the optimal design as well as the operational performance of a group of buildings while minimizing both system costs as well as system emissions. For 52 residential buildings and 82 vehicles, it was chosen to select the optimal vehicle (ICEV, PHEV, BEV, or FCEV), the conversion technologies (HP, gas boilers, PEMFC, PEME, and CMR) and storage technologies (batteries, TES, H2S). A random forest model was also created to predict car ownership in homes based on mobility census data.

The results strongly indicate that combinations of PV, heat pumps, and BEVs are the best alternatives for most homes, although there are certain cases where PHEVs or FCEVs are preferable. PHEVs can be well suited for those who drive only short distances and FCEVs are suited to those that benefit from its longer driving range and fast charging requirements. In terms of emissions reduction, BEVs perform slightly better than FCEVs at a much lower cost. If the capital costs of FCEVs drop in the future, this technology may be come more attractive. In the next steps of this work, a life-cycle analysis for all of the technology components will be performed that will include the embodied emissions of all technologies. In addition, constraints for the draw of power from the 

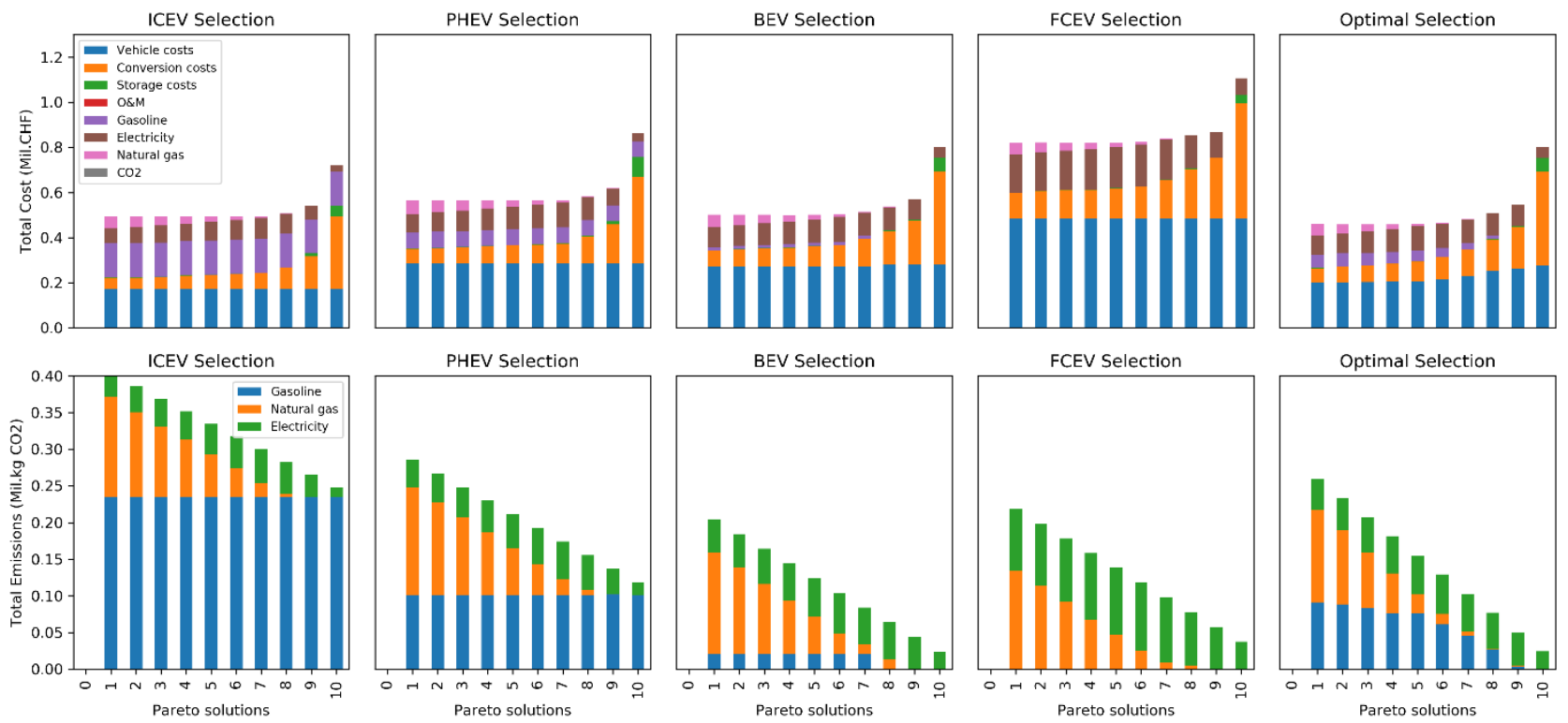

Figure 8: Break down of total costs and emissions by category.

grid to buildings will also be restricted. Due to the nature of electrification of heating via heat pumps and personal transport via BEVs, there is expected to be significant electricity draws from the houses. That has not been simulated in this work, but it would be necessary to include in the following steps to see if this would require exceeding electricity grid requirements.

Lastly, this paper give an assessment of the options for 2018 conditions, however hydrogen, battery, and PV technologies are predicted to decrease in the future. In addition, building loads are predicted to decrease due to resulting a sensitivity analysis looking at the parameters of the model that may change in the future should also be conducted to see how outcomes may change in the future.

\section{Nomenclature}

$\begin{array}{ll}B E V & \text { Battery electric vehicle } \\ C M R & \text { Catalytic methanation reactor } \\ F C E V & \text { Fuel cell electric vehicle } \\ G B & \text { Gas boiler } \\ H P & \text { HP } \\ H 2 S & \text { Hydrogen storage tanks } \\ I C E V & \text { Internal combustion engine vehicle } \\ P E M E & \text { Polymer electrolyte membrane electrolyser } \\ P E M F C & \text { Polymer electrolyte membrane fuel cell } \\ P H E V & \text { Plug-in hybrid electric vehicle } \\ T E S & \text { Thermal energy storage }\end{array}$

\section{Acknowledgement}

This research is part of the Integration of sustainable multienergy hub systems at the neighbourhood scale from the buildings perspective project (IMES-BP 407040-153894) and the Energy Turnaround NRP70 Research Programme. Funding for this project is provided by the Swiss National Science Foundation (SNF).

\section{References}

Bundesamt für Statistik. 2015. Mikrozensus Mobilität Und Verkehr 2015. Neuchatel.
Bundesamt für Statistik, Statistiches Lexikon der Schweiz. 2013. "Gebäude Und Wohnungsregister." Retrieved (https://www.bfs.admin.ch/bfs/de/home.html).

ELCom. 2018. "Strompreis-Webseite Der ElCom." Eidgenössische Elektrizitätskommission ElCom. $\begin{array}{lll}\text { Retrieved January } & 4, & 2018\end{array}$ (https://www.strompreis.elcom.admin.ch/).

Federal Office of Topography swisstopo. 2014. “SwissBUILDINGS3D 2.0." Swiss Confederation. Retrieved November 19, 2016.

FOEN, Federal Office for the Environment. 2018. "CO2 Levy." Retrieved April 30, 2019 (https://www.bafu.admin.ch).

Götz, M., J. Lefebvre, F. Mörs, A. M. Koch, F. Graf, S. Bajohr, R. Reimert, and T. Kolb. 2016. "Renewable Power-to-Gas: A Technological and Economic Review." Renewable Energy 85:1371-90.

Hajimiragha, A., C. Canizares, M. Fowler, M. Geidl, and G. Andersson. 2007. "Optimal Energy Flow of Integrated Energy Systems with Hydrogen Economy Considerations." Pp. 1-11 in Bulk Power System Dynamics and Control - VII. Revitalizing Operational Reliability, 2007 iREP Symposium.

Hofer, J. 2014. "Sustainability Assessment of Passenger Vehicles: Analysis of Past Trends and Future Impacts of Electric Powertrains." ETH Zürich, Zürich.

Kuramochi, T., A. Ramírez, W. Turkenburg, and A. Faaij. 2012. "Comparative Assessment of CO2 Capture Technologies for Carbon-Intensive Industrial Processes." Progress in Energy and Combustion Science 38(1):87-112.

Laumanns, M., Lothar T., and E. Zitzler. 2006. "An Efficient, Adaptive Parameter Variation Scheme for Metaheuristics Based on the Epsilon-Constraint 
Method." European Journal of Operational Research 169(3):932-42.

Marquant, J., R. Evins, and J. Carmeliet. 2015. "Reducing Computation Time with a Rolling Horizon Approach Applied to a MILP Formulation of Multiple Urban Energy Hub System." Procedia Computer Science 51:2137-46.

Mavromatidis, G., K. Orehounig, and J. Carmeliet. 2015. "Evaluation of Photovoltaic Integration Potential in a Village." Solar Energy 121:152-68.

Murray, P., A. Omu, K. Orehounig, and J. Carmeliet. 2017. "Power-to-Gas for Decentralized Energy Systems: Development of an Energy Hub Model for Hydrogen Storage." San Francisco, USA: IBPSA International.

Offer, G., D. Howey, M. Contestabile, R. Clague, and N. Brandon. 2010. "Comparative Analysis of Battery Electric, Hydrogen Fuel Cell and Hybrid Vehicles in a Future Sustainable Road Transport System." Energy Policy 38:24-29.

Tanguy, K., Maxime R. Dubois, K.L. Lopez, and C. Gagné. 2016. "Optimization Model and Economic Assessment of Collaborative Charging Using Vehicle-to-Building." Sustainable Cities and Society 26:496-506.

Wang, D., J. Landolt, G. Mavromatidis, K. Orehounig, and J. Carmeliet. 2018. "CESAR: A Bottom-up Housing Stock Model for Switzerland to Address Sustainable Energy Trans-Formation Strategies' Submitted to Energy and Buildings." Energy and Buildings 169:9-26.

Wi, Y., J. Lee, and S. Joo. 2013. "Electric Vehicle Charging Method for Smart Homes/Buildings with a Photovoltaic System." IEEE Transactions on Consumer Electronics 59(2):323-28. 